\title{
Co-Constructions Of Gender And Ethnicity In \\ New Zealand Television Advertising
}

\author{
By Carolyn Michelle \\ University of Waikato
}

\begin{abstract}
This paper reports key findings from a content analysis of gender and ethnic depictions in a sample of 2,120 New Zealand prime-time television advertisements screened in 2006. The study explored the following questions: With what product categories are male and female White, Māori/Pasifika and Asian characters most commonly associated? What are the most common occupational roles of male and female White, Māori/Pasifika and Asian characters? The results reveal highly stereotypical depictions of women and men within each ethnic category. White men dominated advertisements for foodstuffs, telecommunications and financial/corporate/legal services and were over-represented as professionals/white collar workers, while White women were over-represented in advertisements for household products, personal products, and medical products and featured predominantly as homemakers. Māori/Pasifika men were overrepresented as athletes and service and sales workers. Non-White women featured prominently within multi-ethnic groups in advertisements for personal grooming products and most frequently featured as glamour models, while non-White men were over-represented as blue collar workers. Largely absent were Māori/Pasifika women and Asians of both genders, potentially exacerbating the multiple axes of subordination encountered by these groups in the New Zealand context.
\end{abstract}

Keywords: Television advertising; Gender representations; Ethnic representations; Stereotypes; Intersectional analysis; Content analysis

\section{Introduction}

This study utilises the methodology of content analysis to investigate co-constructions of gender and ethnicity in a sample of 2,120 New Zealand television advertisements screened during August 2006. It follows a small body of work published in this journal (Coltrane \& Messineo, 2000, US; Messineo, 2008, US) that has examined whether there are significant ethnic differences in the representation of women and men in advertising, by analysing the product categories and occupations with which different ethnic groups of women and men are most frequently associated.

Advertising constructs and disseminates idealised representations of women and minority ethnic group members that frequently reflect and reproduce troubling gender and racial stereotypes in terms of the kinds of activities and roles that are seen as appropriate for different groups (Messineo, 2008; Gunter, 1995). Kellner suggests that media products "provide materials out of which we forge our very identities; our sense of selfhood; our notion of what it means to be male or female; our sense of class, of ethnicity and race, or nationality, of sexuality; and of 'us' and 'them"" (Kellner, 1995, p. 9). This view is consistent with cultivation theory, which suggests that repeated exposure to stereotypical images and messages pertaining to gender and ethnicity can shape our attitudes, behaviours and self-perceptions (Gerbner \& Gross, 1976; Gerbner, 1998; Gunter, 1995 , Morgan \& Shanahan, 2010). Social learning theory similarly suggests that television representations provide observational models of gendered behaviour that can shape, in particular, 
children's understandings of the preferred activities and roles for women and men (Bandura, 2002). In the case of ethnic representations, television advertising helps define and maintain the boundaries of 'imagined communities' (Anderson, 1983) and shapes ideas about the shared characteristics and values of ethnic community members. The stereotypes it draws on to quickly convey meaning may be especially influential when dominant group members lack direct exposure to minority ethnic group members to help balance biased or one-dimensional representations. Dyer (1997, p. 12) suggests that stereotyping thereby serves as one of the means by which subordinate groups including women and minority ethnic group members - are "categorised and kept in their place" within wider social, cultural, economic and political power structures.

Given the potential of advertising to shape attitudes, behaviours and perceptions of self and others, along with the suggestion that stereotyping plays a role in perpetuating power inequalities within the wider public domain, it is important to understand the nature and frequency of advertising images and the kinds of products and roles with which different ethnic groups of women and men are most often associated. While international research consistently shows that women are now more visible within television advertising than in the past, albeit still in highly stereotypical ways (Bartsch, Burnett \& Diller et al., 2000, US; Eisend, 2009; Furnham, Babitzkow \& Uguccioni, 2000, France and Denmark; Furnham \& Mak, 1999; Furnham \& Paltzer, 2010; Nassif \& Gunter, 2008, UK and Saudi Arabia; Wolin, 2003), fewer studies have explored whether all women are equally visible, or considered the racial inflections implicit in the product associations and roles that consistently feature in advertisements starring women and men of different ethnicities. Most content analyses of media representation give primacy to one site of difference over the other (most often, gender), or examine each axis separately. Systematic, integrated studies of the simultaneous coconstruction of gender and ethnicity in advertising remain rare (but see Coltrane \& Messineo 2000; Kellner, 1995, UK; Stern, 1999, US). Indeed, in recent special issues of this journal focused on content analysis of gender roles in media, very few articles examined both gender and ethnic representations (but see Turner, 2010, US; Nam, Lee \& Hwang, 2010, South Korea).

This tendency to ignore ethnic differences in advertising representations of women and men is problematic, since it is now widely recognised within cultural studies, critical race studies and gender studies that gender and ethnicity are mutually constituted, interacting sites of social inequality. The social construction of femininities and masculinities is shaped by racialised imagery and discourses, and vice versa (Hill Collins, 2000). Furthermore, the ongoing tendency for social researchers to ignore differences of race and ethnicity among women and men may help perpetuate the invisibility of already marginalised group members, and inadvertently contributes to the discursive naturalization of Whiteness as the 'normal' human state (Dyer, 1997). In that sense, rather than challenging existing social hierarchies of power and dominance, racially-blind research practices potentially reinforce them.

As a useful corrective, the theory and methodology of intersectional analysis offers a conceptualisation of individuals as simultaneously positioned along multiple axes of difference which, rather than being separate and distinct, intersect and interlock in ways that serve to intensify the lived experience of oppression and marginalisation among structurally disadvantaged groups (Crenshaw, 1991; Dill \& Zambrana, 2009). It is this intersectional approach (Crenshaw, 1991) and its capacity to recognise multiple axes of difference among women and men and their implications that is frequently missing in the existing research on advertising depictions of gender and ethnicity. The present study attempted to address this omission by examining co-constructions of gender and ethnicity within New Zealand television advertising.

While a handful of empirical studies have examined gender depictions in New Zealand television advertising (e.g. Desmarais, 2002 and 2007; Furnham \& Farragher, 2000; Gattung, 1984), even fewer have systematically examined television advertising representations of ethnicity, and none offers a detailed analysis of the content of ethnic depictions (but see Hoek \& Laurence, 1991; 
Hoek \& Sheppard, 1990). This lack of local research is somewhat surprising, given that New Zealand has a comparatively large indigenous Māori population (14.6\%) and significant immigrant communities from the Pacific Islands (6.9\%) and Asia (9.2\%) (Statistics New Zealand, 2006). There are also ongoing concerns locally about ethnic marginalisation and racism within New Zealand media more generally (see Ip \& Murphy, 2005; Macpherson \& Spoonley, 2004; Scott, 1990). In order to glean intersectional insight into stereotypical representations of women and men of different ethnicities locally, this research tested a series of hypotheses based on the existing research, and also asked the following exploratory research questions: With what product categories are male and female White, Māori/Pasifika and Asian characters most commonly associated in television advertising? And, what are the most common occupational roles of male and female White, Māori/Pasifika and Asian characters in television advertising?

In seeking answers to these questions, this study contributes to a growing body of international scholarship on gender and ethnic co-constructions in advertising, and specifically builds on intersectional analyses of television advertising published in this journal (Coltrane \& Messineo, 2000; Messineo, 2008). This study also adds to the very small body of existing research on the depiction of indigenous groups in television advertising (Fleras, 1994, Canada; Fleras \& Kunz, 2001, Canada; Higgs \& Milner, 2005, Australia; Luke, 1996, Australia). Thus, it will be of particular interest to scholars working in countries where the lack of visibility accorded to indigenous minorities (and more especially, indigenous women), along with the stereotypical representation of ethnic minorities, are of ongoing concern.

\section{Literature Review and Hypotheses}

Since a growing body of research clearly documents the overwhelming visual dominance of White people in key product representative and speaking roles (discussed below), it seems reasonable to assume that much of the existing disaggregated literature on gender roles in television advertising actually describes the depiction of White women and men, rather than women and men in general. Hence the following review presumes that the large body of international research on gender depictions in advertising can be drawn on, in conjunction with studies of gender and ethnic co-constructions, to describe the nature of television advertising depictions of White women and men more specifically.

Gender depictions in advertising have been well canvassed for more than 30 years (for an overview of international findings, see Bartsch, Burnett \& Diller et al., 2000; Eisend, 2009; Furnham \& Paltzer, 2010; Wolin, 2003). Summarising key findings from comparable studies across five continents, Furnham and Mak (1999) noted that while male characters have traditionally outnumbered female characters in television advertising, women are now more evident in key visual roles and there is currently some inconsistency in the international research on this issue (Das, 2011). However, women remain concentrated in product categories relating to the home, food preparation, personal care and the body, while men are more often seen in advertisements for financial products (Ganahl, Prinsen \& Netzley, 2003, US) and non-domestic products, particularly those related to automobiles and sports (Bartsch et al., 2000; Furnham, et al., 2000; Ganahl et. al, 2003; Nassif \& Gunter, 2008). Studies also consistently show that men are more frequently depicted as powerful, as leaders and as exercising reasoned authority (Beattie, Khan \& Philo, 1998, UK; Coltrane \& Messineo, 2000; Seiter, 1995, US), and appear in a wider range of occupational roles than women (Furnham \& Mak, 1999; Nassif \& Gunter, 2008; Neto \& Pinto, 1998, Portugal). Women are less frequently depicted as professionals or product authorities and remain underrepresented in vocational roles, while being over-represented in maternal, homemaking and aesthetic roles (Furnham \& Mak, 1999; see also Furnham \& Skae, 1997, UK; Gilly, 1988, Australia, Mexico \& US; Nassif \& Gunter, 2008; Neto \& Pinto, 1998). For example, in their cross-cultural comparative study, Paek, Nelson and Vilela (2011) found that in US and Canadian advertisements men were significantly more likely than women to be depicted as professionals and office workers, 
while nearly all those depicted as homemakers were women. However, some recent studies point to signs of change and suggest advertisements now depict women in association with a wider range of product types and in a greater diversity of occupational roles, with more being shown in positions of authority (Bartsch et al., 2000; Furnham \& Skae, 1997).

While only a small body of research exists in New Zealand, findings are broadly consistent with these international trends (see Desmarais, 2002 and 2007; Furnham \& Farragher, 2000; Gattung, 1984; Hoek \& Sheppard, 1990). In the 1984 Media Women survey which this study replicates, men comprised $55 \%$ of main product representatives, while women comprised $35 \%$; in $10 \%$ of cases both genders featured in key visual roles. Of the women product representatives, $59 \%$ featured in advertisements for household products or personal grooming items, and hence the roles in which they appeared were also very limited: $39 \%$ were homemakers, while $28 \%$ were glamour models, meaning that "their main identifiable role was to be glamorous" (Gattung, 1984, p. 2). By comparison, men as product representatives appeared in a much wider range of roles, including professionals (23\%), blue collar workers (13\%), athletes (9\%) and celebrities (8\%) (Gattung, 1984). Men were also spread across a wider range of product categories, although noticeably overrepresented in advertisements for financial/legal/corporate services. More recently, Furnham and Farragher (2000) observed 57\% of central visual figures to be men. They also found that women were more likely to feature in advertisements for body-related products, while men dominated advertisements for auto and sports-related products. Further, women were significantly more often seen in the home and in familial roles (Furnham \& Farragher, 2000). In the most recent study of gender depictions in New Zealand advertising, Desmarais (2007) found that women were frequently portrayed in association with the home and with 'feminine' concerns such as health and beauty, while men were commonly depicted as hyper-masculine and associated with physical and mental toughness. Reflecting consistent trends in the accumulated local and international research described above, the following hypotheses were formulated in relation to representations of women and men in New Zealand television advertising:

H1: Women will be under-represented as main product representatives (Desmarais, 2007; Gattung, 1984; Furnham \& Farragher, 2000). The rational for H1 is that while some recent overseas studies suggest an increase in the visibility of women, New Zealand studies consistently document their under-representation in key visual roles. H1 will be tested by comparing the observed numbers of women and men depicted in this key visual role, using expected frequencies that presume gender equality (i.e. $50 \%$ for each gender).

$\mathrm{H} 2$ : White men will be over-represented as sole product representatives in advertisements for financial/corporate/legal services (following Ganahl, Prinsen \& Netzley, 2003; Gattung, 1984). H2 will be tested by comparing the number of White men depicted in this product category with figures for all other gender/ethnic groups combined, using expected frequencies based on the overall proportion of White men versus all other groups (see Table 2).

H3: White men will be over-represented in the occupational roles of professional/white collar worker and blue collar worker (following Gattung, 1984; Paek, Nelson \& Vilela, 2011). H3 will be tested by comparing the numbers of White men depicted in each occupational role with figures for all other gender/ethnic groups combined, using the same expected frequencies as outlined above.

H4: White women will be over-represented as sole product representatives in advertisements for personal products and personal grooming products (following Desmarais, 2007; Furnham \& Farragher, 2000; Furnham \& Mak, 1999). H4 will be tested by comparing the numbers of White women depicted in each product category with figures for all other gender/ethnic groups combined, using expected frequencies based on the overall proportion of White women versus all other groups. 
H5: White women will be over-represented in the occupational roles of homemaker and glamour model (following Gattung, 1984; Furnham \& Mak, 1999; Paek, Nelson \& Vilela, 2011). H5 will be tested by comparing the numbers of White women depicted in each occupational role with figures for all other gender/ethnic groups combined, using the same expected frequencies as outlined above.

As previously noted, much of the research on advertising representations of gender assumes that the categories 'women' and 'men' are singular and homogeneous. Hence, very few studies have offered insight into how various different ethnic groups of women and men are depicted assuming they appear at all. In exploring how representations of gender and ethnicity are simultaneously co-constructed, it was anticipated that the results of this research would echo studies from the US, UK, Canada, and Australia documenting the under-representation and stereotypical representation of women and non-White ethnic groups. While international comparisons can be somewhat problematic given New Zealand's social, cultural and political specificity, many important historical, cultural and institutional similarities can be assumed due to New Zealand's shared Anglo-Saxon heritage as a former British colony, Commonwealth member, and predominantly English-speaking country (Burd-Sharps, Lewis, Guyer \& Lechterman, 2010). As 'liberal' welfare states, New Zealand, Australia, Canada, the UK and US are frequently grouped together in analyses of family, social and economic policy (e.g. see Bolzendahl \& Olafsdottir, 2008; Kamerman \& Kahn, 1987; Burds-Sharps et al., 2010). A significant proportion of television programmes (and some advertisements) broadcast locally are produced in the US, UK, and Australia (Bell, 1995; Horrocks, 2004). The US, Australia and Canada also have minority indigenous populations which face similar problems to Māori following colonisation (Havemann, 1999; Daniel, Cargo, \& Marks, et al., 2009). Thus, while co-constructions of gender and ethnicity are clearly shaped by aspects that are specific to New Zealand's current cultural and geopolitical location, research from the US, UK, Canada and Australia potentially provides useful points for comparison and thus both sets of literature are drawn on in the following review.

The 1984 Media Women survey was the first major New Zealand study to record the ethnicity of television advertising product representatives, and noted the overwhelming predominance of Pākeha (White Europeans) in key visual roles (Gattung, 1984). Indeed, Media Women recorded more animals depicted as sole product representatives $(3 \%)$ than persons of identifiably Māori descent $(1 \%)$, other ethnicities $(2 \%)$, or multiple product representatives of mixed ethnicities $(2 \%)$ (Ibid.). More recent small-scale content analyses offer some support to these impressions regarding the marginalisation of non-White ethnic groups locally. Hoek and Sheppard (1990) analysed 69 New Zealand advertisements screening during children's programming in 1989 and found that $95 \%$ featured only or mainly White characters as dominant characters, while 5\% were considered equally balanced in terms of their ethnic representation. None of the advertisements featured predominantly Māori or other ethnicities in key roles. However, a larger study subsequently undertaken by Hoek and Laurence (1991) suggested rapid improvement. In a sample of 148 advertisements, 74\% featured predominantly White characters, while $23 \%$ were neutral or balanced in their ethnic composition. Again, however, only a tiny proportion (3\%) featured predominantly non-White people as dominant characters.

While very little empirical research has been conducted on ethnic representations in television advertising locally, this topic has been the subject of discussion and considerable concern over the past three decades. While in the 1980s local advertising executives openly acknowledged the conscious, routine exclusion of Māori and Pasifika people from advertisements on the grounds of a lack of 'image appeal' (Scott, 1990), scholars such as Macpherson and Spoonley (2004) suggest the under-representation of ethnic minorities started to be addressed from the 1990s as advertisers became more mindful of the growing consumer power of local indigenous and migrant communities. However, others observe that any new 'visibility' has not been uniformly accorded, but rather, remains explicitly gendered. For instance, Earl (2005) suggests recent changes reflect the 
strategic cooption of young male Polynesian rap and hip hop artists within glocalised advertising campaigns for multinationals such as Coca-cola, McDonalds and Nike. Polynesian women, conversely, remain marginalised, highly stereotyped, and most frequently associated with "nature, family and the body" (p. 12). The complex interactions between gender and ethnicity in New Zealand are also noted by Wall (1997), Falcous (2007) and Scherer and Jackson (2008), who illustrate how recent marketing campaigns have utilised hyper-masculine depictions of Māori men's sporting prowess to evoke imagery of the ferocious 'native' warrior. Wall (1997) suggests such depictions potentially reinforce stereotypical constructions of Māori men as 'natural' athletes, genetically suited to physical (rather than intellectual) activities (see also Hooks, 1992; Jackson, 1994). The relative invisibility of Asians within local media has also been noted (Benson, 2006; Ip \& Murphy, 2005). To date, however, large scale empirical studies have been lacking in New Zealand, and thus the present study offers essential quantitative evidence to inform this ongoing debate.

The above observations, while largely anecdotal, clearly resonate with those drawn from the international scholarship, which documents the under-representation of non-White ethnic groups in countries with White majorities. While non-White people are increasingly visible, they most frequently appear in the background in minor, non-speaking roles, and are granted less power and authority than Whites (Beattie, Khan \& Philo, 1998, UK; Bramlett-Solomon \& Roeder, 2008, US; Bristor, Lee \& Hunt, 1995, US; Frith \& Mueller, 2003, US; Henderson \& Baldasty, 2003, US; Mastro \& Stern, 2006, US; Taylor \& Stern, 1997, US; Wilkes \& Valencia, 1989, US). Studies from the US and UK also suggest non-White people appear more often in mixed-race groups, and that entirely non-White advertisements remain unusual (Bramlett-Solomon \& Roeder, 2008; Taylor, 1997, US/UK). As Henderson \& Baldasty (2003) note in relation to the US, ethnic or 'multicultural' presence is typically balanced by the inclusion of White characters among the cast. Based on these local and international findings, the following hypothesis was formulated in relation to the New Zealand context:

H6: White women and men will be more likely than non-White women and men to appear as main product representatives. H6 will be tested by comparing the observed numbers of Whites versus non-Whites in this key visual role, using expected frequencies based on 2006 population statistics.

Research also suggests that depictions of non-White people in key visual roles are often highly stereotypical and generally support dominant group values and norms (Coltrane \& Messineo, 2000; Greenberg, Mastro \& Brand, 2002, US; Wilson \& Gutierrez, 1995, US). For example, Coltrane and Messineo's (2000) research suggests that US television commercials tend to portray "White men as powerful, White women as sex objects, African American men as aggressive, and African American women as inconsequential" (p. 363). Local representations of Polynesians are likely to bear some similarities to depictions of African Americans, for a number of reasons. Politically, Māori were strongly influenced by the US Black Power Movement during the early 1970s, with calls for Maori self-determination fuelling a contemporary 'renaissance' of Māori culture, language and politics (Poata-Smith, 1996). In both contexts, the political, economic and cultural aspirations of a significant ethnic minority have received some degree of formal acknowledgement: in the US, affirmative action has helped expand opportunities for African Americans, while in New Zealand the preferred strategy has been parallel development (Ringold, 2008). The New Zealand Government formally recognises the Treaty of Waitangi (signed between Māori and the British Crown in 1840), Māori or te reo is an official language, a parallel State-funded Māori education system exists, and The Māori Party has served as a coalition partner in successive governments (Cleave, 2009; Mutu, 2010). Further, as Earl (2005) has noted, there are similarities in terms of how local advertisers have appropriated Māori and Polynesian rap and hip-hop music (itself inspired by African American youth culture) in order to define 'hip', 'cool', 'street-wise' consumerism for White New Zealand youth, echoing the appropriation of African American music and dance forms 
in the US (see Henderson \& Baldasty, 2003; Seiter, 1995). For these reasons, research on depictions of African Americans (and to a lesser extent given New Zealand's colonial history, Black British) is likely to be of relevance to advertising representations of Māori and Pasifika peoples locally.

Summarising the existing research, African American characters tend to be most visible in advertisements for low-cost, low-nutrition foodstuffs (Henderson \& Baldasty, 2003; Li-Vollmer, 2002, US; Mastro \& Stern, 2003), cheap clothing, alcohol, entertainment products, sporting equipment, and athletic apparel (Bramlett-Solomon \& Roeder, 2008). Henderson and Baldasty (2003) suggest such associations potentially affirm stereotypes of African Americans as less responsible, less focused on good nutrition, and less home-focused. These findings are echoed in studies of advertising depictions of Black British by Taylor (1997) and Beattie, Khan and Philo (1998). Taylor (1997) notes that in the UK, Black people most often feature in advertisements for entertainment products (particularly dance music), food and drink, and automobile-related products, while Beattie, Khan and Philo (1998) found that non-White people were less often cast as professionals and more often as musicians and sportspersons, and were more frequently seen performing manual tasks and wearing 'exotic' costumes. Indeed, numerous studies document prevalent stereotypes of Black people as 'natural athletes' (particularly Black men), and as talented musicians, dancers and entertainers (Bramlett-Solomon \& Roeder, 2008; Coltrane \& Messineo, 2000; Seiter, 1995; Taylor, 1997). Further, both Black British and African Americans are overrepresented in public service announcements (Bramlett-Solomon \& Roeder, 2008; Henderson \& Baldasty, 2003; Li-Vollmer, 2002; Taylor, 1997), although as Taylor (1997) observes, they typically feature as those receiving advice, not those giving it. Further, while African American men's 'natural' sporting prowess appears to have granted them "symbolic access to some of the instrumental benefits of [hegemonic] masculinity" (Coltrane \& Messineo, 2000, p. 385), African American women are rarely shown exerting authority, and their beauty is less revered than White women's (Coltrane \& Messineo, 2000). Also evident in the body of existing research is the lack of visibility accorded to non-White women (Courtney \& Whipple, 1983, US), who, at least according to US research, are less often seen than men of the same ethnicity (Coltrane \& Messineo, 2000; Mastro \& Stern, 2006; Taylor \& Stern, 1997).

Since Māori are the indigenous people of New Zealand, the specific nature of their depiction may also bear some similarities to the depiction of indigenous groups in other former British colonies such as Australia, the US, and Canada. Based on the little international research that exists, it is clear that indigenous peoples remain very poorly represented. In one of very few quantitative studies, Higgs and Milner (2005, p. 63) found that Australian aboriginals remained largely invisible in television advertising. This finding is echoed by Mastro and Stern $(2003,2006)$, who note the gross under-representation of Native Americans in US commercials. Frequently, portrayals of indigenous people are highly stereotypical. For example, while indigenous Australians do feature prominently in tourism advertising, they almost always appear in traditional costume as performers and cultural artefacts associated with the land, 'tribalism' and 'nativism' (Luke, 1996). Likewise, Fleras (1994) notes that Canadian First Nations people, and more especially men, are most frequently typecast within media as 'the noble savage,' the 'blood-thirsty barbarian', and 'the drunken Native' (see also Fleras \& Kunz, 2001). Far less is recorded about the depiction of indigenous women. Given these trends in the representation of African Americans and indigenous women and men, and their possible relevance to the depiction of Māori and Pasifika women and men locally, the following hypotheses were generated:

H7: Māori/Pasifika women and men will be under-represented in relation to their actual proportion of the New Zealand population. H7 will be tested by comparing the observed numbers of Māori/Pasifika women and men in key visual roles with figures for all other gender/ethnic groups combined, using expected frequencies based on 2006 population statistics, when Māori/Pasifika people comprised 21.5\% of the New Zealand population. 
H8: Māori/Pasifika men will be over-represented in the occupational categories of athlete and celebrity (following Bramlett-Solomon \& Roeder, 2008; Coltrane \& Messineo, 2000). H8 will be tested by comparing the numbers of Māori/Pasifika men depicted in each occupational category with figures for all other gender/ethnic groups combined, using expected frequencies based on the overall proportion of Māori/Pasifika men versus all other groups.

H9: Māori/Pasifika women will be less visible than Māori/Pasifika men (following Coltrane \& Messineo, 2000; Courtney \& Whipple, 1983; Mastro \& Stern, 2006; Taylor \& Stern, 1997). H9 will be tested by comparing the observed numbers of Māori/Pasifika women and men depicted in key visual roles, using expected frequencies that presume gender equality (i.e. $50 \%$ for each gender).

New Zealand has a long history of Asian settlement, beginning in the late $19^{\text {th }}$ century. People of Asian ethnicities now comprise a significant proportion of the population $-9.2 \%$ in 2006 . However, their historical presence in New Zealand has, until recently, received little public recognition. Further, as Benson (2006), Ip and Murphy (2005) and Macpherson and Spoonley (2004) all note, Asian immigration has recently become the subject of some public and political disquiet. While there exist no published content analyses of Asian representations in New Zealand television advertising, related research suggests Asians have served as the dominant ethnic group's 'ultimate Other' through their repeated stereotypical depiction as competing with 'real Kiwis' for scarce resources, as perpetrators and victims of crime, as engaging in deviant behaviour, and as commodities (e.g. full-fee paying foreign students) (Benson, 2006; Cormack, 2007).

In terms of the international research, US research suggests Asian-Americans are significantly more likely than other ethnicities to be cast in minor non-speaking roles rather than as product representatives, and most often feature in the background as anonymous minority faces in a crowd (Coltrane \& Messineo, 2000; Mastro \& Stern 2003, 2006; Taylor \& Stern, 1997). This general pattern has also been identified in relation to depictions of Asians in Australian television (Higgs \& Milner, 1995). Wilson and Gutierrez (1995) note historically prevalent depictions in the US of Asian men as business men or martial artists, and Asian women as seductive china dolls or geishas. But as Cohen (1992) notes, Asians are now more often regarded in the US as the 'model minority' (as cited in Taylor \& Stern, 1997), and this is reflected within advertising via positive stereotypes of Asian-Americans as intelligent, disciplined and hardworking over-achievers, as having scientific, mathematical and technological aptitude, and as affluent, educated, professionals (BramlettSolomon \& Roeder, 2008; Mastro \& Stern, 2003; Taylor \& Stern, 1997). Also of note is that Asian-American women remain less visible than Asian men, and, unlike White women, are less often shown as sex objects (Coltrane \& Messineo, 2000) or at home (Taylor \& Stern, 1997). Based on the existing international research and local discussions of Asian visibility in New Zealand, various hypotheses were formulated. However, due to an almost complete absence of relevant depictions, only one was able to be tested:

H10: Asian women and men will be under-represented in relation to their actual proportion of the New Zealand population. H10 will be tested by comparing the observed numbers of Asian women and men depicted as main product representatives with figures for all other gender/ethnic groups combined, using expected frequencies based on 2006 population statistics, when Asian people comprised $9.2 \%$ of the New Zealand population.

\section{Research Questions}

As this review of existing research reveals, very little is currently known about the frequency and specific content of television advertising depictions of women and men of different ethnicities in New Zealand. Furthermore, there is some degree of uncertainty about the relevance of international research findings locally, and in particular, whether representations of Māori/Pasifika women and men will be consistent with those of African Americans, or other indigenous groups, or 
a combination both. For these reasons, this study sought more specific insight into the ways gender and ethnicity are mutually co-constructed in television advertising locally. To guide this process, two additional exploratory research questions were formulated:

RQ1: With what product categories are male and female White, Māori/Pasifika and Asian characters most commonly associated in television advertising?

RQ2: What are the most common occupational roles of male and female White, Māori/Pasifika and Asian characters in television advertising?

Method

\section{The Sample}

The sample for the present study comprised 2,120 advertisements screened during prime-time (6 p.m. - 10 p.m.) on TVOne and TV2, New Zealand's highest rating national television channels. Advertisements were recorded in 2006 over the same 14-day period used in the 1984 Media Women survey, from August $8^{\text {th }}-22^{\text {nd }}$. Apart from trailers for other television shows or movies, all product advertisements were coded, including repeat screenings, as this provides a better indication of the predominance of certain kinds of representations (Taylor, 1997; Wilkes \& Valencia, 1989). All calculations in this paper are thus based on the frequency of "message units" (Gattung, 1984, p. 1).

\section{Coding Procedure}

As shown in Table 1, coders recorded details of the gender and ethnicity of the visible main product representative(s) and secondary characters (men, women, both, other). The main product representative was defined as the figure (usually an actor, but in some cases a celebrity, athlete, official spokesperson, animal or animation) that was most closely visually associated with the product in terms of talking about, using, demonstrating, playing with, eating or wearing the product. Where two or more individuals shared this key role, any details that differed among them (i.e. gender or ethnicity) were recorded. Secondary characters were defined as those that interacted with the main product representative or the product in some way (not necessarily verbally), or were in another capacity part of the action/story telling of the advertisement. Coders also recorded the status of secondary characters in terms of their number and apparent relationship to each other and/or the main product representative(s). Ethnic categories included White/Pākeha, Māori/Pasifika, other, Asian, and mixed ethnicity groups; coders also recorded the number of animals in key roles. The ethnic category of 'Māori' was expanded to include 'Pasifika peoples' for reasons discussed below, while the category 'Asian' was added to Media Women's original schedule due to recent immigration trends in New Zealand. Coders also recorded information on any visible occupations performed by product representative(s) (see Table 1 for the full list of sub-categories). Product type was coded using a 11-product coding scheme based on that used by Media Women, but updated to reflect the emergence of 'new' product categories such as telecommunications (i.e. mobile phones and calling plans). 
Table 1. Variables and Interrater Agreement. ${ }^{a b}$

\begin{tabular}{|c|c|c|c|}
\hline Variable & Description & $\begin{array}{l}\text { Interrater } \\
\text { Agreement }\end{array}$ & $\begin{array}{l}\text { Scott's Pi } \\
\text { Value }\end{array}$ \\
\hline $\begin{array}{l}\text { Sex of main product } \\
\text { representative(s): }\end{array}$ & Male; Female; both; animated & $100 \%$ & 1.0 \\
\hline $\begin{array}{l}\text { Sex of secondary/ } \\
\text { background characters: }\end{array}$ & Male; Female; both; animated & 99.0 & .96 \\
\hline $\begin{array}{l}\text { Ethnicity of main product } \\
\text { representative(s): }\end{array}$ & $\begin{array}{l}\text { White; Māori/Pasifika; other; Asian; } \\
\text { mixed ethnicities; animal }\end{array}$ & 93.0 & .90 \\
\hline $\begin{array}{l}\text { Ethnicity of secondary/ } \\
\text { background characters: }\end{array}$ & $\begin{array}{l}\text { White; Māori/Pasifika; other; Asian; } \\
\text { mixed ethnicities; animal }\end{array}$ & 92.0 & .89 \\
\hline $\begin{array}{l}\text { Secondary character } \\
\text { status: }\end{array}$ & $\begin{array}{l}\text { One character; two characters; } \\
\text { several unrelated; family members; } \\
\text { animated }\end{array}$ & 96.0 & .95 \\
\hline Product type: & $\begin{array}{l}\text { Household products (cleaning } \\
\text { products); personal hygiene; personal } \\
\text { grooming; financial/corporate/legal } \\
\text { services; retail; foodstuffs; medical; } \\
\text { Do-it-yourself/Building supplies; } \\
\text { public service announcements; } \\
\text { telecommunications; other }\end{array}$ & 93.0 & .92 \\
\hline $\begin{array}{l}\text { Occupation of main } \\
\text { product representative(s): }\end{array}$ & $\begin{array}{l}\text { Homemaker; professional/white } \\
\text { collar worker; blue colour worker; } \\
\text { clerical worker; athlete; glamour } \\
\text { model; service/sales worker; } \\
\text { celebrity; other; none }\end{array}$ & 92.0 & .91 \\
\hline
\end{tabular}

${ }^{\text {a }}$ Only variables relevant to this analysis are reported here.

${ }^{\mathrm{b}}$ Average interrater agreement across all variables was $93.0 \%$.

\section{Coder Reliability}

A senior undergraduate student and graduate research assistant served as coders. They were provided with an explanation of the coding schedule and variables before undergoing training using 40 advertisements that did not form part of the main sample. They then met with the researcher to discuss and resolve areas of disagreement. To determine interrater reliability, $10 \%$ of the main sample was independently coded by each coder and then analysed by the researcher. Interrater reliability statistics for each major variable discussed in this paper are presented in Table 1. Overall, interrater agreement was 93\% across all variables; Scott's Pi values for variables discussed in this paper ranged from .89 to 1.0. Given the large number of sub-categories within the coding scheme, these figures were considered acceptable. In remaining cases of disagreement in the coding of that proportion of the main sample that was double-coded, the researcher evaluated the relevant advertisements independently and decided on the final coding to be included in the analysis.

Given that both coders were White women, it is important to acknowledge the biases that may arise from relying on White perceptions and categorisations of ethnic 'Others' - not the least being the perpetuation of racial stereotypes and modes of ethnic homogenisation. This is especially relevant in the case of depictions of Māori/Pasifika peoples, as many Pākeha New Zealanders experience difficulty in accurately distinguish between members of closely related Polynesian groups. Hence the original category of 'Māori' used by Media Women was expanded to include 
'Pasifika peoples'. While employing Māori/Pasifika coders may have helped resolve this issue, it cannot be assumed that ethnic group membership inevitably translates into accurate identification of other group members, especially since research suggests that non-White people more often feature briefly and in background roles. That said, while inter-coder reliability was high for this variable (93\%), the potential for collective coder inaccuracies in distinguishing the ethnicities of non-White others is acknowledged.

\section{Results}

Since the data were frequencies, chi-square goodness-of-fit analyses were conducted to determine the degree to which the research hypotheses were supported. Unless otherwise stated, chi-squares compare actual versus expected ratios for each group in the given categories, with expected ratios being based on the overall gender and ethnic distribution figures provided in Table 2, or in some cases extrapolated by combining data relating to specific combinations of groups. In most cases, the chi-square analyses seek to test whether, given the existing (unequal) population distribution of different gender and ethnic groups across the sample as a whole, there was any further significant ethnic or gender patterning in the distribution of those groups within categories and sub-categories. Because in many cases the cell counts were below the chi-square minimum frequency requirement (5), it was necessary to combine the figures for all gender and ethnic groups other than the group being tested to perform valid chi square analyses relating to $\mathrm{H} 2-\mathrm{H} 5$ and $\mathrm{H} 8$. For example, if testing the statistical significance of the under-representation of White women in a particular occupational category, figures relating to observed and expected frequencies of 'White women' and 'all other groups combined' were used. In the section entitled Comparative Analysis, data relating to all non-White women and all non-White men were combined to permit valid statistical analysis. Unless otherwise stated, chi-square calculations exclude data relating to advertisements in which animals, animations, and both men and women featured as main product representatives.

Table 2. Gender and Ethnicity of Main Product Representatives

\section{Ethnicity}

\begin{tabular}{|c|c|c|c|c|c|c|}
\hline & $\begin{array}{l}\text { White } \\
N=1110\end{array}$ & $\begin{array}{l}\text { Māori/ } \\
\text { Pasifika } \\
N=42\end{array}$ & $\begin{array}{l}\text { Other } \\
\text { Ethnicities } \\
N=34\end{array}$ & $\begin{array}{l}\text { Asian } \\
N=0\end{array}$ & $\begin{array}{l}\text { Mixed } \\
N=124\end{array}$ & $\begin{array}{l}\text { Animal } \\
N=16\end{array}$ \\
\hline \multicolumn{7}{|l|}{ Gender } \\
\hline Men $N=459$ & 403 & 33 & 6 & 0 & 17 & 0 \\
\hline Proportion $^{a}$ & $38.2 \%$ & $3.1 \%$ & $0.6 \%$ & & $1.6 \%$ & \\
\hline Women $N=599$ & 528 & 5 & 12 & 0 & 50 & 4 \\
\hline Subtotal (excluding animals) & $50.1 \%$ & $0.5 \%$ & $1.1 \%$ & & $4.7 \%$ & - \\
\hline$N=1054$ & $88.3 \%$ & $3.6 \%$ & $1.7 \%$ & & $6.4 \%$ & \\
\hline Both $N=228$ & 165 & 4 & 2 & 0 & 56 & 1 \\
\hline Animated $N=40$ & 14 & 0 & 14 & 0 & 1 & 11 \\
\hline TOTAL $N=1326$ & $83.7 \%$ & $3.2 \%$ & $2.6 \%$ & & $9.4 \%$ & $1.2 \%$ \\
\hline
\end{tabular}

a These proportions exclude animated or animal main product representatives, and advertisements containing mixed-gender pairs or groups as main product representatives. $N=$ 1054. 


\section{Gender of Main Product Representatives}

Following Gattung (1984) and Furnham and Farragher (2000), Hypothesis 1 predicted that women would be under-represented as main product representatives. This was tested using the aggregated figures for all women and all men, which were compared with expected frequencies of $50 \%$ for each group. On that basis, women were in fact more often seen in advertisements with sole or all-women product representatives $(56.5 \%)$ than were men $(43.5 \%), X^{2}(1, N=1054)=17.55$, $p<.0001$. Thus, H1 was not supported; men were actually underrepresented as main product representatives, consistent with some recent international studies (e.g. Kim \& Lowry, 2005, South Korea). However, further analysis reveals that the product categories and occupations with which women and men are associated remain highly stereotypical. Furthermore, there are striking inequalities in the visibility accorded to different ethnic groups of women and men, with some groups being virtually absent from key visual roles.

Table 3. Gender, Ethnicity, and Product Categories

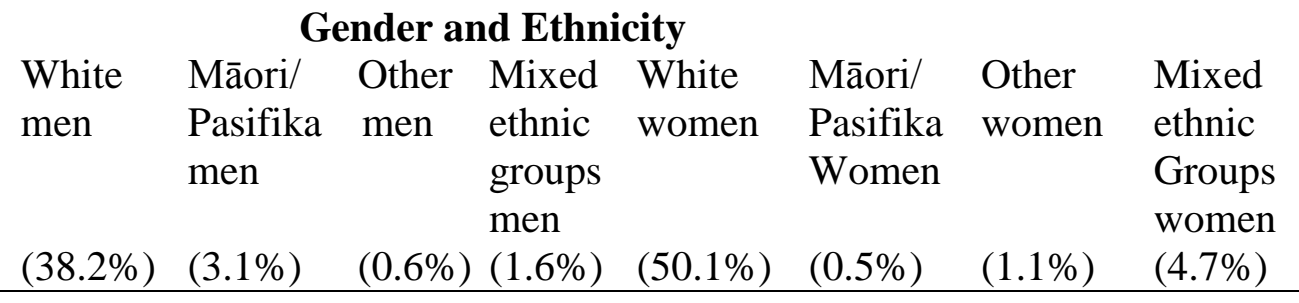

\begin{tabular}{|c|c|c|c|c|c|c|c|c|}
\hline Product & & & & & & & & \\
\hline $\begin{array}{l}\text { Household products } \\
\qquad(\mathrm{n}=80) \text { Row } \%\end{array}$ & $\begin{array}{l}9 \\
11.3\end{array}$ & 0 & 0 & 0 & $\begin{array}{l}71 \\
88.8\end{array}$ & 0 & 0 & 0 \\
\hline $\begin{aligned} \text { Personal products } \\
(\mathrm{n}=37) \%\end{aligned}$ & $\begin{array}{l}3 \\
8.1\end{array}$ & 0 & 0 & 0 & $\begin{array}{l}34 \\
91.9\end{array}$ & 0 & 0 & 0 \\
\hline $\begin{array}{l}\text { Personal grooming } \\
\qquad(\mathrm{n}=189) \%\end{array}$ & $\begin{array}{l}20 \\
10.6\end{array}$ & $\begin{array}{l}1 \\
0.5\end{array}$ & 0 & 0 & $\begin{array}{l}113 \\
59.8\end{array}$ & 0 & $\begin{array}{l}12 \\
6.3\end{array}$ & $\begin{array}{l}43 \\
22.8\end{array}$ \\
\hline $\begin{array}{l}\text { Financial/ corporate/ } \\
\text { legal services } \\
\qquad(\mathrm{n}=69) \%\end{array}$ & $\begin{array}{l}48 \\
69.6\end{array}$ & 0 & 0 & $\begin{array}{l}5 \\
7.2\end{array}$ & $\begin{array}{l}15 \\
21.7\end{array}$ & $\begin{array}{l}1 \\
1.4\end{array}$ & 0 & 0 \\
\hline Retail $(\mathrm{n}=158) \quad \%$ & $\begin{array}{l}55 \\
34.8\end{array}$ & $\begin{array}{l}4 \\
2.5\end{array}$ & 0 & 0 & $\begin{array}{l}93 \\
58.9\end{array}$ & 0 & 0 & $\begin{array}{l}6 \\
3.8\end{array}$ \\
\hline $\begin{array}{r}\text { Foodstuffs }(\mathrm{n}=257) \\
\%\end{array}$ & $\begin{array}{l}133 \\
51.8\end{array}$ & $\begin{array}{l}10 \\
3.9\end{array}$ & $\begin{array}{l}5 \\
1.9\end{array}$ & $\begin{array}{l}8 \\
3.1\end{array}$ & $\begin{array}{l}99 \\
38.5\end{array}$ & $\begin{array}{l}1 \\
0.3\end{array}$ & 0 & $\begin{array}{l}1 \\
0.3\end{array}$ \\
\hline Medical $(\mathrm{n}=108)$ & $\begin{array}{l}39 \\
36.1\end{array}$ & $\begin{array}{l}2 \\
1.9\end{array}$ & 0 & 0 & $\begin{array}{l}66 \\
61.1\end{array}$ & $\begin{array}{l}1 \\
0.9\end{array}$ & 0 & 0 \\
\hline $\begin{array}{l}\text { DIY/building supplies } \\
\qquad(\mathrm{n}=57) \%\end{array}$ & $\begin{array}{l}37 \\
64.9\end{array}$ & $\begin{array}{l}8 \\
14.0\end{array}$ & 0 & 0 & $\begin{array}{l}12 \\
21.1\end{array}$ & 0 & 0 & 0 \\
\hline $\begin{array}{l}\text { Public service } \\
\text { announcements } \\
\qquad(\mathrm{n}=28) \%\end{array}$ & $\begin{array}{l}10 \\
35.7\end{array}$ & $\begin{array}{l}4 \\
14.3\end{array}$ & 0 & $\begin{array}{l}3 \\
10.7\end{array}$ & $\begin{array}{l}9 \\
32.1\end{array}$ & $\begin{array}{l}2 \\
7.1\end{array}$ & 0 & 0 \\
\hline $\begin{array}{l}\text { Telecommunications } \\
\qquad(\mathrm{n}=31) \%\end{array}$ & $\begin{array}{l}30 \\
96.8\end{array}$ & 0 & 0 & 0 & $\begin{array}{l}1 \\
3.2\end{array}$ & 0 & 0 & 0 \\
\hline Other $(\mathrm{n}=40)$ & $\begin{array}{l}19 \\
47.5\end{array}$ & $\begin{array}{l}4 \\
10.0\end{array}$ & $\begin{array}{l}1 \\
2.5\end{array}$ & $\begin{array}{l}1 \\
2.5\end{array}$ & $\begin{array}{l}15 \\
37.5\end{array}$ & 0 & 0 & 0 \\
\hline
\end{tabular}


Table 4. Gender, Ethnicity, and Occupations

\section{Gender and Ethnicity}

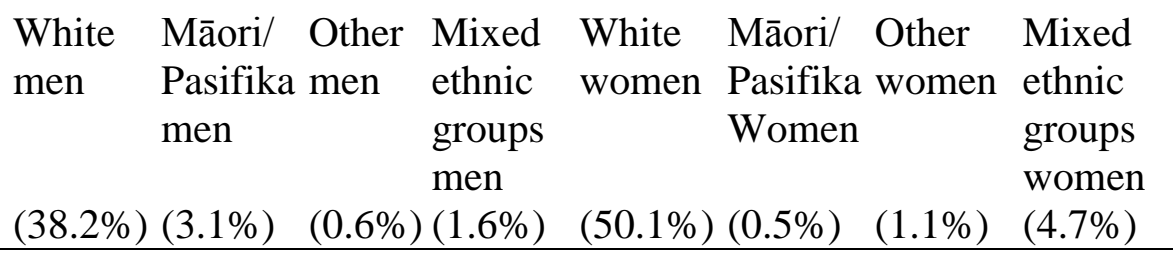

\begin{tabular}{|c|c|c|c|c|c|c|c|c|}
\hline $\begin{array}{l}\text { Occupation } \\
\text { Homemaker }(\mathrm{n}=83) \\
\qquad \text { Row } \%\end{array}$ & $\begin{array}{l}2 \\
2.4\end{array}$ & 0 & 0 & 0 & $\begin{array}{l}81 \\
97.6\end{array}$ & 0 & 0 & 0 \\
\hline $\begin{array}{l}\text { Professional/White Collar } \\
\text { Worker }(\mathrm{n}=47) \quad \%\end{array}$ & $\begin{array}{l}28 \\
59.6\end{array}$ & 0 & 0 & $\begin{array}{l}5 \\
10.6\end{array}$ & $\begin{array}{l}14 \\
29.8\end{array}$ & 0 & 0 & 0 \\
\hline $\begin{array}{l}\text { Blue Collar Worker } \\
\qquad(\mathrm{n}=29) \%\end{array}$ & $\begin{array}{l}17 \\
58.6\end{array}$ & $\begin{array}{l}1 \\
3.4\end{array}$ & 0 & $\begin{array}{l}8 \\
27.6\end{array}$ & $\begin{array}{l}3 \\
10.3\end{array}$ & 0 & 0 & 0 \\
\hline Clerical Worker $(\mathrm{n}=38)$ & $\begin{array}{l}12 \\
31.6\end{array}$ & 0 & 0 & 0 & $\begin{array}{l}26 \\
68.4\end{array}$ & 0 & 0 & 0 \\
\hline Athlete $(\mathrm{n}=50)$ & $\begin{array}{l}27 \\
54.0\end{array}$ & $\begin{array}{l}10 \\
20.0\end{array}$ & 0 & 0 & $\begin{array}{l}11 \\
22.0\end{array}$ & $\begin{array}{l}1 \\
2.0\end{array}$ & 0 & $\begin{array}{l}1 \\
2.0\end{array}$ \\
\hline $\begin{array}{r}\text { Glamour Model }(\mathrm{n}=123) \\
\%\end{array}$ & $\begin{array}{l}17 \\
13.8\end{array}$ & $\begin{array}{l}1 \\
0.8\end{array}$ & 0 & 0 & $\begin{array}{l}60 \\
48.8\end{array}$ & 0 & $\begin{array}{l}2 \\
1.6\end{array}$ & $\begin{array}{l}43 \\
35.0\end{array}$ \\
\hline $\begin{array}{l}\text { Service/Sales Worker } \\
\qquad(\mathrm{n}=90) \%\end{array}$ & $\begin{array}{l}42 \\
46.7\end{array}$ & $\begin{array}{l}10 \\
11.1\end{array}$ & $\begin{array}{l}1 \\
1.1\end{array}$ & 0 & $\begin{array}{l}36 \\
40\end{array}$ & $\begin{array}{l}1 \\
1.1\end{array}$ & 0 & 0 \\
\hline Celebrity $(n=119)$ & $\begin{array}{l}40 \\
33.6\end{array}$ & $\begin{array}{l}6 \\
5.0\end{array}$ & 0 & 0 & $\begin{array}{l}63 \\
52.9\end{array}$ & 0 & $\begin{array}{l}10 \\
8.4\end{array}$ & 0 \\
\hline Other $(\mathrm{n}=76)$ & $\begin{array}{l}22 \\
28.9\end{array}$ & 0 & 0 & $\begin{array}{l}1 \\
1.3\end{array}$ & $\begin{array}{l}53 \\
69.7\end{array}$ & 0 & 0 & 0 \\
\hline None $(n=399)$ & $\begin{array}{l}196 \\
49.1\end{array}$ & $\begin{array}{l}5 \\
1.3\end{array}$ & $\begin{array}{l}5 \\
1.3\end{array}$ & $\begin{array}{l}3 \\
0.7\end{array}$ & $\begin{array}{l}181 \\
45.4\end{array}$ & $\begin{array}{l}3 \\
0.7\end{array}$ & 0 & $\begin{array}{l}6 \\
1.5\end{array}$ \\
\hline
\end{tabular}

\section{White men.}

White men appeared on their own or in all-White male groups in $38.2 \%$ of advertisements containing human product representatives $(n=403)$. H2 predicted that White men would be overrepresented as sole product representatives in advertisements for financial/corporate/legal services. In order to test this, data for White women and all other categories of non-White women and men were combined, giving a total of 21 and an expected frequency of $61.8 \%$. On this basis, $\mathrm{H} 2$ was supported, as White men comprised $69.6 \%(\mathrm{n}=48)$ of main product representatives in this category, $X^{2}(1, N=69)=28.75, p<.0001$. This is consistent with the findings of Ganahl et al. (2003) and Gattung (1984).

Further analysis of product categories relating to RQ1 revealed that White men were most significantly over-represented in the new product category of telecommunications products, where 
they comprised $96.8 \%(n=30)$ of all product representatives. While it was not possible to test this degree of over-representation, White men's almost complete dominance of this category is a striking reiteration of historical associations between White masculinity, reasoned authority, technological innovation and control (Seiter, 1995; Wajcman, 1991). Importantly, their visual dominance of this category does not reflect any actual gender differences in men's and women's use of telecommunications products New Zealand. A large scale survey on ICT use conducted between 2004-2006 found no significant gender differences in either internet usage or mobile phone ownership, but did document lower levels of ICT usage among Māori and Pasifika men and women (Statistics New Zealand, 2007). White men were also comparatively over-represented in advertisements for DIY/building supplies $(64.9 \%, \mathrm{n}=37), X^{2}(1, \mathrm{~N}=57)=17.23, p<.0001$. It is important to note however that the product category in which White men most frequently featured was actually foodstuffs $(n=133)$ (Table 3$)$. Further, while relatively few men were representatives for household products, personal products, or personal grooming items (combined total $n=33$ ), all but one of those who featured were White men (Table 3).

H3 predicted that White men would be over-represented in the occupational roles of professional/white collar worker and blue collar worker. This was supported: White men were comparatively over-represented in the categories of professional/white collar worker $(\mathrm{n}=28$, $59.6 \%), X^{2}(1, N=47)=9.10, p=.003$ and also blue collar worker $(\mathrm{n}=17,58.6 \%), X^{2}(1, N=29)=$ $5.12, p=.02$. However, further analysis relating to RQ2 showed that the occupations in which White men were most frequently seen were service or sales worker $(n=42,46.7 \%)$ and celebrity $(n=40$, $33.6 \%$ ). Only two White men featured as homemakers in this sample (2.4\%), while 17 featured as glamour models in advertisements for personal grooming products (13.8\%).

\section{White women.}

White women were the most visible group, featuring as product representatives alone or in allWhite female groups in $50.1 \%$ of advertisements containing human product representatives $(\mathrm{n}=$ 528). H4 predicted that White women would be over-represented as sole product representatives in advertisements for personal products and personal grooming products. This was tested in relation to all other groups combined $(\mathrm{n}=525 ; 49.9 \%)$. On that basis, H4 was supported in the first instance, as White women were very much over-represented as product representatives in advertisements for personal products $(\mathrm{n}=34,91.9 \%)$, although it was not possible to formally test this. They were also significantly over-represented as product representatives in advertisements for personal grooming items $(\mathrm{n}=113,59.8 \%), X^{2}(1, N=189)=7.10, p=.008$. That White women's presence was also most strongly concentrated in advertisements for personal grooming items $(21.4 \%$ of all White women product representatives appeared in this category) attests to the continued emphasis placed on physical appearance for White women and the consumption work required to attain the contemporary ideal of feminine beauty. That said the proportion of women overall concentrated in this category has declined since the Media Women survey of 1984.

Further analysis relating to RQ1 revealed that White women were also very significantly overrepresented as main product representatives in advertisements for household products $(\mathrm{n}=71$; $88.8 \%), X^{2}(1, N=80)=47.80, p<.0001$, and to a lesser extent medical products $(61.1 \%), X^{2}(1, N=$ $108)=5.24, p=.02$. The product categories in which White women were most frequently featured also largely reflect and reiterate traditional areas of responsibility for White women given their historical construction as mothers and homemakers. Some $18.8 \%$ of White women product representatives appeared in advertisements for foodstuffs $(n=99)$, and while it is noteworthy that they were significantly under-represented in this category relative to White men $(\mathrm{n}=133), X^{2}(1, N$ $=232)=18.59, p<.0001$, the data relating to White women's and men's occupations suggest the two groups are likely to be positioned rather differently within this category - women being more often depicted as homemakers, primarily responsible for purchasing and preparing food products for family consumption. White women were also featured prominently in advertisements for retail 
products $(\mathrm{n}=93 ; 17.6 \%$ of all advertisements with White women as product representatives), and household products (primarily cleaning products) $(\mathrm{n}=71 ; 13.4 \%)$.

H5 predicted that White women would be over-represented in the occupational roles of homemaker and glamour model. This hypothesis was only partially supported. White women were most often depicted as homemakers $(n=81)$, and made up the overwhelming majority of all those depicted in this role $(97.6 \%)$; as such, it was not possible to conduct a formal test for significance. However, while many White women appeared as glamour models $(n=60)$, they comprised only $48.8 \%$ of all those shown in this role as sole product representatives, and hence were not in fact statistically overrepresented, $X^{2}(1, N=123)=0.09, p=0.8, n s$. It is important to note, however, that White women were also featured among mixed ethnicity groups of women, and that women as $a$ group $(\mathrm{n}=105)$ were significantly overrepresented in this occupational role relative to men as a group, $X^{2}(1, N=123)=41.70, p<.0001$. Further analysis relating to RQ2 indicates that White women were over-represented to a greater degree in the occupational category of clerical workers (n $=26 ; 68.4 \%), X^{2}(1, N=38)=5.10, p=.02$, an occupational category from which non-White people were entirely absent.

For almost all other ethnic groups of women and men, statistical analysis becomes unreliable due to the very small numbers depicted. Hence, data relating to all non-White women and all nonWhite men have been combined below for the purposes of comparative analysis. However, it remains important to discuss the implications of the patterns identified in the depiction of Māori/Pasifika and Asian women and men, and to consider these patterns in light of broader trends found within relevant international research on ethnic representations in advertising.

\section{Ethnic Representations}

H6 predicted that White women and men would be more likely than non-White women and men to appear as main product representatives. The present study suggests improvements have been made in terms of the visibility of non-White groups since the 1984 Media Women survey, although little has changed in terms of their prominence, as White characters continue to dominate key visual roles. Overall, $83.7 \%$ of all advertisements with product representatives (including animals and animations) showed only White people as main product representatives (see Table 2). Given that current population statistics reveal $31.7 \%$ of New Zealanders to be self-identified members of a non-White ethnic group, leaving a balance of $68.3 \%$ with no such affiliations (Statistics New Zealand, 2006), this is clearly a significant degree of over-representation of White people in key visual roles, $X^{2}(1, N=1326)=145.44, p<.0001$. H6 was thus supported.

H7, which predicted that Māori/Pasifika women and men would be under-represented in key visual roles in relation to their actual proportion of the New Zealand population, was also supported. Māori/Pasifika peoples, who together comprise $21.5 \%$ of the population (Statistics New Zealand, 2006), rarely appeared as product representatives without the presence of Whites or other ethnicities: Just 3.2\% of all advertisements showed only Māori/Pasifika peoples in the key role of sole product representative (Table 2). While Māori/Pasifika people may have been featured in some advertisements with two or more product representatives of different ethnicities, they remain significantly under-represented in this key role, appearing as product representatives in, at most, $12.6 \%$ of advertisements (including those with both men and women as product representatives) and probably far less than this. To test this prediction, figures relating to animals, animations and mixed ethnicity groups were excluded from the calculation (since the latter may or may not have included any particular ethnicity), but advertisements with both men and women as product representatives were included. This gives a revised frequency for Maori/Pasifika peoples of 3.6\% $(n=42)$ versus an expected frequency of $21.5 \%$, with a combined expected frequency for all other ethnic groups of $78.5 \%(\mathrm{n}=1116)$. On that basis, the degree of underrepresentation is highly significant, $X^{2}(1, N=1158)=219.18, p<.0001$. 
Additionally, while Asians now comprise 9.2\% of New Zealand's population (Statistics New Zealand, 2006), no Asians were featured as sole product representatives within a sample of 2,120 advertisements. If they appeared at all, it was in the $9.4 \%$ of advertisements containing multiple product representatives of mixed ethnicities, or in the background of advertisements as part of a multi-ethnic casts of 'Others'. Of the 880 advertisements that featured secondary characters, only two had identifiably Asian characters. H10, which predicted that Asian women and men would be under-represented in relation to their actual proportion of the New Zealand population, was thus clearly supported. However, due to the degree of invisibility of Asians, the statistical significance of this finding could not be formally tested. The magnitude of this lack of Asian representation is heightened when one considers the number of advertisements that featured as main product representatives either animated characters $(3.0 \%)$ or animals $(1.2 \%)$. Evidently, New Zealand advertisers are reluctant to feature Asian men or women as the sole representative for their product, a sentiment reflected in Scott's (1990) survey of senior New Zealand advertising executives, some of whom openly expressed the view that certain ethnic groups lacked 'image appeal'. Further, while mainstream White audiences are often presumed to have difficulty identifying with ethnic 'Others' (Scott, 1990), apparently no such difficulty is perceived in them identifying with amorous pots of yoghurt, talking rolls of toilet tissue, or quacking ducks, all of which featured as main product representatives in the advertisements sampled.

\section{Māori/Pasifika women and men.}

While Māori/Pasifika men fared considerably better than Māori/Pasifika women, they remained significantly under-represented and were depicted as sole or single-ethnicity product representatives in $3.1 \%$ of advertisements $(n=33)$, a significant level of under-representation relative to actual population levels. Māori/Pasifika women were even less visible, and featured as sole product representatives in just five $(0.5 \%)$ advertisements (Table 2). Excluding advertisements which featured both genders, animals or animations and assuming gender equality, the expected frequency for Māori/Pasifika men and women was 19 for each group (50\%). H9, which predicted that Māori/Pasifika women would be less visible than their male counterparts, was thus supported, $X^{2}(1$, $N=38)=20.63, p<.0001$.

H8 predicted that Māori/Pasifika men would be over-represented in the occupational categories of athlete and celebrity. This hypothesis was only partially supported; nearly a third of the Māori/Pasifika men who were featured as sole product representatives were athletes $(n=10)$ and they made up $20.0 \%$ of all those seen in this occupation, a significant degree of over-representation relative to all other groups combined $(96.9 \%), X^{2}(1, N=50)=47.54, \mathrm{p}<.0001$. Conversely, while there were six Māori/Pasifika men depicted as celebrities $(5.0 \%)$ they were not statistically overrepresented in this category, $X^{2}(1, N=119)=1.49, p=.2, n s$.

Further analyses relating to RQ1 and RQ2 aimed to shed further light on the product categories and occupations that Māori/Pasifika men and women were most frequently associated with. Māori/Pasifika men were significantly over-represented among service and sales workers $(\mathrm{n}=10$, $11.1 \%), X^{2}(1, N=90)=19.23, p^{<.0001}$, and were most frequently featured as product representatives in a limited range of categories - foodstuffs $(n=10)$, DIY/building supplies $(n=8)$, retail $(n=4)$, and public service announcements $(n=4)$ (Table 3$)$. They were significantly overrepresented in advertisements for DIY/building supplies, comprising $14.0 \%$ of all those seen in this product category, $X^{2}(1, N=57)=22.69, p=<.0001$. In the case of Māori/Pasifika women, little has changed since 1984: there were still more animated characters and animals observed in the role of sole product representative than real Māori/Pasifika women. Given such low numbers for this group, their data is combined with that relating to all non-White women (below). 


\section{Mixed-ethnicity groups of women and men.}

Further analysis relating to RQ1 discovered that, of the 50 advertisements featuring groups of women of various ethnicities as product representatives, 43 were advertisements for personal grooming items (Table 3). Multi-ethnic casts of women represented $22.8 \%$ of the advertisements in this product category, a significant level of over-representation given that multi-ethnic groups of women comprised $4.7 \%$ of main product representatives overall, while all other groups combined had an expected frequency of $95.3 \%, X^{2}(1, N=189)=137.50, p<.0001-$ although it should be noted that White women also appeared within these multi-ethnic casts. This finding contradicts Henderson and Baldasty's (2003, p. 104) finding that only $6.2 \%$ of US advertisements for cosmetics contained non-White people in any role.

Considering RQ2, where an occupation was visible in these advertisements, it was invariably that of the glamour model $(n=43)$ : Multi-ethnic groups of women comprised $35.0 \%$ of all those depicted in this capacity, a very significant degree of over-representation, $X^{2}(1, N=123)=251.44$, $p<.0001$. Furthermore, while fewer multi-ethnic groups of men were visible as product representatives $(\mathrm{n}=17,1.6 \%)$, they appeared in connection with a more diverse range of products, including foodstuffs $(n=8)$, financial/corporate/legal services $(n=5)$, and public service announcements $(\mathrm{n}=3)$ (Table 3). The most common occupations depicted in advertisements featuring multi-ethnic groups of men as product representatives were blue collar worker $(\mathrm{n}=8)$ and professional or White collar worker $(n=5)$ (Table 4).

\section{Comparative analysis of White versus non-White women and men.}

Given the small numbers involved, for statistical purposes the data relating to all non-White women and all Non-White men were combined to ascertain whether there were marked differences in the product categories in which White versus non-White women and men appeared and the occupations with which each group was most often associated. Clear patterns emerged that shed further light on RQ1 and RQ2. Non-White women $(n=67 ; 11.3 \%$ of women product representatives overall) were featured in a very narrow range of product categories; $82.1 \%$ of advertisements were for personal grooming items $(n=55)$. By contrast, White women $(n=528$; $88.7 \%$ of women product representatives overall) featured in this product category only $21.4 \%$ of the time, and were well represented in several other categories. Non-White women were thus significantly more likely to feature as product representatives in the personal grooming category than were White women on their own, $X^{2}(1, N=168)=77.03, p<.0001$.

White women and men as a group ( $\mathrm{n}=931 ; 88.3 \%)$ completely dominated key visual roles in advertisements for household products and personal products, a category from which non-White women and men $(\mathrm{n}=123 ; 11.7 \%)$ were entirely absent. This is in keeping with the findings of Henderson and Baldasty (2003) and Mastro and Stern (2003) in the US. Since household products were primarily cleaning products, and personal products related mainly to hygiene, the strong historical association between Whiteness, cleanliness and hygiene appears to be reinforced within this sample (Dyer, 1997). Furthermore, this racial association is simultaneously gendered, since White women were significantly over-represented in both product categories. Non-White men were also absent from key visual roles in advertisements for telecommunications technology, a product category that was almost completely dominated by White men, further reinforcing historically prevalent associations between technological competence and hegemonic White masculinity (Wajcman, 1991).

Further analysis relating to RQ2 found that where a discernable occupation was evident, nonWhite women almost always featured as glamour models $(\mathrm{n}=45 ; 77.6 \%$ of all non-White women product representatives) or celebrities $(\mathrm{n}=10 ; 17.2 \%)$. Given their overall level of underrepresentation as a group, they were significantly over-represented relative to White women in the former category, $X^{2}(1, N=105)=104.32, p<.0001$. If an occupation was evident, White women 
most often featured as homemakers $(n=81 ; 23.3 \%)$, while non-White women were entirely invisible in this capacity. Non-White women were also absent as professionals/White collar workers and as clerical workers; on only one occasion did a non-White woman feature as a service or sales worker. By comparison, 76 advertisements featured White women in these three occupational categories.

In the case of non-White men ( $\mathrm{n}=56 ; 12.2 \%$ of men product representatives overall), $41.1 \%$ of the advertisements in which they were featured were for foodstuffs $(n=23)$. However, this was not significantly different to the proportion of White men $(n=403 ; 87.8 \%)$ who featured in this major product category $(\mathrm{n}=133 ; 33.0 \%), X^{2}(1, N=156)=0.94, p=0.3$, ns. Where a discernable occupation was present, non-White men most often featured as service and sales workers $(\mathrm{n}=11$; $25.6 \%$ of all non-White men product representatives), athletes $(\mathrm{n}=10 ; 23.3 \%)$, blue collar workers $(n=9 ; 20.9 \%)$, and celebrities $(n=6 ; 14.0 \%)$. Relative to White men, they were significantly overrepresented as blue collar workers, comprising $34.6 \%$ of all men shown in this role, $X^{2}(1, N=26)=$ $12.20, p=.0005$, and as athletes $(27.0 \%), X^{2}(1, N=37)=7.59, p=.006$. Non-White men were entirely absent as clerical workers, and on only one occasion did a non-White man feature as a glamour model. By comparison, White men featured in these capacities in 29 advertisements. Finally, $76.8 \%$ of non-White men product representatives were shown to have a discernable occupation, compared with just $51.4 \%$ of White men - a significant difference, $X^{2}(1, N=250)=$ 5.84, $p=.02$. While this might be viewed as a positive development, non-White men remained significantly under-represented as a group. The patterns identified in this study are also consistent with international research, and in fact attest to the ongoing assignment of non-White men to a limited range of highly stereotypical roles within advertising - as menial labourers, athletes, and service workers - rather than any broader recognition that these men might suitably represent the 'average' consumer.

\section{Discussion}

The findings of this study of 2,120 advertisements reveal that gender and ethnicity intersect to produce significant differences in the frequency and content of advertising representations of different ethnic groups of women and men. Furthermore, these findings challenge some widely accepted understandings of gender representations in television advertising, and demonstrate the value of an intersectional approach. Most notably, historical connections linking masculinity with the public domain, reasoned authority, and technological innovation and control were visually reinforced only in the case of White men, who featured more often than non-White men in advertisements reflecting these qualities and in higher status occupations such as professionals/white collar workers. While Furnham, et al. (2000, France \& Denmark), Gilly (1988, Australia, Mexico \& US) and Kim and Lowry (2005, South Korea) all document the increasing visibility of women in advertising, who now outnumber men in some contexts, this study reveals that it is White women, more specifically, who predominate visually. As Pyke and Johnson (2003, p. 35) suggest, "axes of domination, such as race, class, sexuality, and age, mould a hegemonic femininity that is venerated and extolled in the dominant culture, and that emphasizes the superiority of some women over others, thereby privileging White upper-class women". Such privileging was evident in this sample, as White women featured alone or in all-White groups of product representatives in $88.7 \%$ of the advertisements with just women in this key visual role. However, White women also remained heavily concentrated in product categories that reaffirm this group's socially ascribed responsibilities for unpaid domestic labour, along with the heteronormative imperative to consume in the service of feminine beautification, and were most often seen as homemakers and in advertisements for personal grooming products.

Patterns also emerged in the depiction of non-White men which resonate with the findings of other studies suggesting men of color are now more visible, but are often represented in highly stereotypical ways - mainly as entertainers, 'natural' athletes, or menial labourers (e.g. Bramlett- 
Solomon \& Roeder, 2008, US). While Māori/Pasifika peoples were more visible than indigenous groups in other countries (Higgs \& Milner, 2005, Australia; Mastro \& Stern, 2003, US) the nature of their representation remains problematic. Scott (1990) has observed the tendency for well-known Māori/Pasifika actors and entertainers to feature predominantly in local advertisements for DIY/hardware products, a category in which this group was indeed over-represented. Further, Wall (1997) identifies the prevailing racialised discourse whereby Māori have been stereotypically imagined within local media as naive comic Others - echoing the 'comic buffoon' stereotype identified in relation to African Americans (Hall, 2003; Hooks, 1992) - noble savages, and 'primitive' natural athletes. As Wall notes, the suggestion that Polynesian men are 'natural' athletes is essentially the same stereotype applied to Black men (Hooks, 1992; Jackson, 1994), and in both cases implies that they are genetically better suited to physical activities, rather than intellectual ones (Wall, 1997). This persistent recurring stereotype is potentially damaging in the local context, especially since it is articulated alongside other negative stereotypes of Māori and Pasifika peoples as state dependents and as having a higher propensity towards criminality (Wall, 1997).

Contrary to the findings of Henderson and Baldasty (2003, US), non-White women were overrepresented as glamour models, perhaps reflecting a growing desire on the part of the cosmetics industry to maximise its international market reach by giving all women, regardless of race or place, "permission to buy" (Berry, 1991; as cited in Frith \& Mueller, 2003, p. 123). Further, non-White women remained largely absent from roles associated with caring for the home and with family life - consistent with studies by Coltrane and Messineo (2000, US) and Taylor and Stern (1997, US \& UK). Also noteworthy is that there continued to be more animals cast in key visual roles than real Māori/Pasifika women - a telling reflection of the extent of this group's ongoing cultural, economic and political marginalisation. Asians of either gender were also entirely absent as sole product representatives. Overall, the degree of under-representation of non-White men and women was so marked that it was only possible to tentatively identify broader trends in the depiction of Māori/Pasifika masculinities, while no reliable information was generated about Māori/Pasifika femininities, nor Asian masculinities and femininities, other than clear evidence of the significant degree of under-representation of these groups.

The relative lack of visibility accorded to non-White women and men in New Zealand advertising is concerning, particularly given the role that media representations are believed to play in shaping understandings of Self, others, and community membership. In addition, scholars have expressed concern that a lack of diversity within media and advertising imagery may bolster feelings of superiority and entitlement among dominant group members, whilst encouraging "subtle forms of prejudice, and institutional racism" (Coltrane \& Messineo, 2000, p. 385) as well as sexism within the wider culture. As Hill Collins (2000) suggests, Whiteness is normalised and privileged through mainstream culture's dissemination of 'controlling images' of non-White femininities and masculinities, reflected in historically prevalent media stereotypes. Further, as Messineo (2008) observes, while significant advances have been made in recent decades, "the media does far more to foster prejudice against women and minorities than to overcome it... This is especially true of imagery that involves the confluence of gender and race" (p. 753; emphasis added). The relevance of an intersectional approach to studying advertising representations is further underscored by evidence that for subordinate group members, narrow and distorted depictions as well as a scarcity of images have the potential to foster feelings of alienation and social exclusion (Higgs \& Milner, 2005). Given their marginalisation from cultural production, subordinate group members must often rely on and may internalise images and definitions produced and disseminated by the dominant group (Pyke \& Johnson, 2003). While these images may provide sources of meaning and selfidentification, they are simultaneously framed by and affirm hegemonic interests.

It is clear from the findings of this study that New Zealand television advertising continues to offer a narrow set of highly stereotypical depictions of different ethnic groups of women, and also men. From an intersectional perspective, such trends in the distribution and nature of advertising 
representations may help bolster prevailing social hierarchies whereby certain groups of ethnic women (and non-hegemonic or 'feminised' ethnic minority men) encounter multiple axes of subordination, in turn perpetuating their cultural, economic and political marginalisation. In effect, these patterns of representation reinscribe hegemonic social relations and broader social, cultural, economic and political processes whereby difference is turned into dominance. By collectively constructing White women and men as the most prominent and authoritative figures while relegating those of other ethnicities to minor background roles, if they are seen at all, the advertisements in this sample not only naturalised Whiteness as the norm, but more subtly offered visual justification for non-White ethnic groups' inequitable access to power and resources within the wider society. Collectively, these advertisements overtly reproduced racial and gender stereotypes and biases. As a pervasive cultural form, advertising may in this way operate to constrain possibilities and aspirations for social transformation and for the realisation of full social, economic, political and symbolic equality between women and men of all ethnicities.

\section{References}

Anderson, B. (1983). Imagined communities: Reflections on the origin and spread of nationalism. London: Verso.

Bandura, A. (2002). Social cognitive theory of mass communication. In J. Bryant \& D. Zillmann (Eds.), Media effects: Advances in theory and research (pp. 121-154). Mahwah, NJ: Erlbaum.

Bartsch, R., Burnett, T., Diller, T., \& Rankin-Williams, E. (2000). Gender representation in television commercials: Updating an update. Sex Roles, 43, 735-743. doi: 10.1023/A:1007112826569

Beattie, L., Khan, F. \& Philo, G. (1998). Race, advertising and the public face of television. In G. Philo (Ed.), Message received: Glasgow Media Group research, 1993-1998 (pp. 149-170). New York: Longman.

Bell, A. (1995). An endangered species: Local programming in the New Zealand television market. Media, Culture \& Society, 17, 181-200. doi: 10.1177/016344300022003001

Benson, S. (2006). Commodification of Asian international students in radio media discourse. New Zealand Journal of Asian Studies, 8, 96-109.

Bolzendahl, C. \& Olafsdottir, S. (2008). Gender group interest or gender ideology? Understanding U.S. support for family policy within the liberal welfare regime. Sociological Perspectives, 51, 281-304.

Bramlett-Solomon, S. \& Roeder, Y. (2008). Looking at race in children's television. Journal of Children and Media, 2, 56-66. doi:10.1080/17482790701733187

Bristor, J., Lee, R. G. \& Hunt, M. (1995). Race and ideology: African-American images in television advertising. Journal of Public Policy and Marketing, 14, 48-59.

Burd-Sharps, S., Lewis, K., Guyer, P. \& Lechterman, T. (2010). Twenty years of human development in six affluent countries: Australia, Canada, Japan, New Zealand, the United Kingdom, and the United States. United National Development Programme Human Development Reports Research Paper 2010/27. New York, NY: UNDP.

Cleave, P. (2009). Starting points? A discussion of contemporary Maori society and culture. Te Kaharoa, 2, 116-129.

Coltrane, S. \& Messineo, M. (2000). The perpetuation of subtle prejudice: Race and gender imagery in 1990s television advertising. Sex Roles, 42, 363-389. doi: 10.1023/A:1007046204478 
Cormack, D. (2007). Once an Other, always an Other: Contemporary discursive representations of the Asian Other in Aotearoa/New Zealand. (Doctoral dissertation). University of Waikato, Hamilton, New Zealand.

Courtney, A. \& Whipple, T. (1983). Sex stereotyping in advertising. Lexington: Lexington Books.

Crenshaw, K. (1991). Mapping the margins: Intersectionality, identity politics, and violence against women of color. Stanford Law Review, 43, 1241-1299. Retrieved from http://www.jstor.org/stable/1229039

Daniel, M., Cargo, M., Marks, E., Paquet, C., Simmons, D., Williams, M., Rowley, K., \& O’Dea, K. (2009). Rating health and social indicators for use with indigenous communities: A tool for balancing cultural and scientific utility. Social Indicators Research, 94, 241-256. doi $10.1007 / \mathrm{s} 11205-008-9420-7$

Das, M. (2011). Gender role portrayals in Indian television ads. Sex Roles, 64, 208-222. doi 10.1007/s11199-010-9750-1

Desmarais, F. (2002). Authority versus seduction: The use of voice-overs in New Zealand and French television advertising. In J. Farnsworth \& I. Hutchinson (Eds.), New Zealand television: A reader (pp. 156-171). Palmerston North: Dunmore Press.

Desmarais, F. (2007). Advertisements as tourism space: 'Learning' masculinity and femininity from New Zealand television. In A. Pritchard, N. Morgan, I. Ateljevic, \& C. Harris (Eds.), Tourism and gender: Embodiment, sensuality and experience (pp. 207-218). Oxfordshire: CABI.

Dill, B. \& Zambrana, R. (Eds.) (2009). Emerging intersections: Race, class, and gender in theory, policy and practice. New Brunswick, NJ: Rutgers University Press.

Dyer, R. (1997). White. London and New York: Routledge.

Earl, E. (2005, July). Brand New Zealanders: The commodification of Polynesian youth identity in television advertising. Paper presented at the annual conference of the Australian and New Zealand Communication Association, Christchurch, New Zealand.

Eisend, M. (2009). A meta-analysis of gender roles in advertising. Journal of the Academy of Marketing Science, 38, 418-440. doi: 10.1007/s11747-009-0181-X

Falcous, M. (2007). The decolonizing national imaginary: Promotional media constructions during the 2005 Lions tour of Aotearoa New Zealand. Journal of Sport and Social Issues, 31, 374393. doi: $10.1177 / 0193723507307820$

Fleras, A. (1994). Media and minorities in a post-multicultural society: Overview and appraisal. In J. W. Berry \& J. A. LaPonce (Eds.), Ethnicity and culture in Canada: The research landscape (pp. 267-292). Toronto: University of Toronto Press.

Fleras, A., \& J. Kunz. (2001). Media and minorities: Representing diversity in a multicultural Canada. Toronto: Thompson Educational Publishing Inc.

Frith, K. \& Mueller, B. (2003). Advertising and societies: Global issues. New York: Peter Lang.

Furnham, A., Babitzkow, M., \& Uguccioni, S. (2000). Gender stereotyping in television advertisements: A study of French and Danish television. Genetic, Social, and General Psychology Monographs, 26, 79-102.

Furnham, A. \& Mak, T. (1999). Sex-role stereotyping in television commercials: A review and comparison of fourteen studies done on five continents over 25 years. Sex Roles, 41, 413-437. doi: 10.1023/A:1018826900972

Furnham, A., \& Farragher, E. (2000). A cross-cultural content analysis of sex-role stereotyping in television advertisements: A comparison between Great Britain and New Zealand. Journal of 
Broadcasting and Electric Media, 44, 415-436.

Furnham, A., \& Paltzer, S. (2010). The portrayal of women and men in television advertisements: An updated review of 30 studies published since 2000. Scandinavian Journal of Psychology, 51, 216-236. doi: 10.1111/j.1467-9450.2009.00772.x

Furnham, A., \& Skae, E. (1997). Changes in the stereotypical portrayal of men and women in British television advertisements. European Psychologist, 2, 44-51.

Ganahl, D., Prinsen, T. \& Netzley, S. (2003). A content analysis of prime time commercials: A contextual framework of gender representation. Sex Roles, 49, 545-551. doi:10.1023/A:1025893025658

Gattung. T. (1984). Images of women in advertising: The reality gap. Wellington: Media Women.

Gerbner, G. (1998). Cultivation analysis: An overview. Mass Communication Research, 3-4, 175194.

Gerbner, G., \& Gross, L. (1976). Living with television: The violence profile. Journal of Communication, 26, 173-199. doi:10.1111/j.1460-2466.1976.tb01397.x

Gilly, M. (1988). Sex roles in advertising: A comparison of television advertisements in Australia, Mexico and the United States. Journal of Marketing, 52, 75-85.

Greenberg, B. Mastro, D. \& Brand, J. (2002). Minorities and the mass media: Television into the $21^{\text {st }}$ century. In J. Bryant \& D. Zillmann (Eds.), Media effects: Advances in theory and research (pp. 333-351). Mahway, NJ: Lawrence Erlbaum Associates.

Gunter, B. (1995). Television and gender representation. London: John Libbey.

Hall, S. (2003). The whites of their eyes: Racist ideologies and the media. In G. Dines \& J. Humez (Eds.), Gender, race, and class in media (pp. 89-93). Thousand Oaks, California: Sage Publications.

Havemann, P. (1999). Indigenous peoples' rights in Australia, Canada, and New Zealand. Melbourne: Oxford University Press.

Henderson, J. J. \& Baldasty, G. (2003). Race, advertising, and prime-time television. The Howard Journal of Communications, 14, 97-112. doi:10.1080/10646170304267

Higgs, B. \& Milner, L. (2005). Portrayals of cultural diversity in Australian television commercials: A benchmark study. Paper presented at the ANZMAC Conference, Freemantle, Australia. Retrieved from http://eprints.vu.edu.au/877/1/1-Higgs.pdf

Hill Collins, P. (2000). Black feminist thought. New York: Routledge.

Hoek, J. \& Laurence, K. (1991). Television advertising to children: An analysis of selected New Zealand commercials. Marketing Bulletin, 4, 19-29.

Hoek, J. \& Sheppard, W. (1990). Stereotyping in advertisements viewed by children. Marketing Bulletin, 1, 7-12.

hooks, b. (1992). Black looks: Race and representation. Boston: South End Press.

Horrocks, R. (2004). Turbulent television: The New Zealand experiment. Television \& New Media, 5, 55-68. doi: 10.1177/1527476403259742

Ip, M. \& Murphy, N. (2005). Aliens at my table: Asians as New Zealanders see them. Auckland: Penguin Books.

Jackson, P. (1994). Black male: advertising and the cultural politics of masculinity. Gender, Place and Culture, 1, 49-59. doi:10.1080/09663699408721200 
Kamerman, S. \& Kahn, A. (Eds.) (1987). Family change and family policies in Great Britain, Canada, New Zealand and the United States. Oxford: Carendon Press.

Kellner, D. (1995). Cultural studies, multiculturalism and media culture. In G. Dines \& J. Humez (Eds.), Gender, race and class in media (pp. 5-17). Thousand Oaks, California: Sage.

Kim, K. \& Lowry, D. (2005). Television commercials as a lagging social indicator: Gender role stereotypes in Korean television advertising. Sex Roles, 53, 901-910. doi:10.1007/s11199005-8307-1

Li-Vollmer, M. (2002). Race representation in child-targeted television commercials. Mass Communication and Society, 5, 207-228. doi: 10.1207/S15327825MCS0502_6

Luke, C. (1996). Reading gender and culture in media discourses and texts. In G. Bull \& M. Anstey (Eds.), The literacy lexicon (pp. 177-192). New York/ Sydney: Prentice-Hall.

Macpherson, C. \& Spoonley, P. (2004). Mediated ethnicity: Media and the management of ethnic images in Aotearoa. In P. Spoonley, C. Macpherson \& D. Pearson (Eds.), Tangata tangata: The changing ethnic contours of New Zealand (pp. 221-244). Southbank, Australia: Thomson/Dunmore Press.

Mastro, D. \& Stern, S. (2003). Representations of race in television commercials: A content analysis of prime-time advertising. Journal of Broadcasting and Electronic Media, 47, 638647.

Mastro, D. \& Stern, S. (2006). Race and gender in advertising: A look at sexualized images in prime-time commercials. In T. Reichert \& J. Lambiase (Eds.), Sex in consumer culture: the erotic content of media and marketing (pp. 281-300). Mahwah, NJ: Lawrence Erlbaum.

Messineo, M. (2008). Does advertising on Black entertainment television portray more positive gender representations compared to broadcast networks? Sex Roles, 59, 752-764. doi: 10.1007/s11199-008-9470-y

Morgan, M. \& Shanahan, J. (2010). The state of cultivation. Journal of Broadcasting \& Electronic Media, 54, 337-355. doi 10.1080/08838151003735018

Mutu, M. (2010). Māori Issues. The Contemporary Pacific, 22, 179-184.

Nam, K, Lee, G., \& Hwang, J. (2010). Gender stereotypes depicted by Western and Korean advertising models in Korean adolescent girls' magazines. Sex Roles, 64, 223-237. doi: $10.1007 / \mathrm{s} 11199-010-9878-\mathrm{Z}$

Nassif, A. \& Gunter, B. (2008). Gender representation in television advertisements in Britain and Saudi Arabia. Sex Roles, 58, 752-760. doi: 10.1007/s11199-008-9394-6

Neto, F. \& Pinto, I. (1998). Gender stereotypes in Portuguese television advertisements. Sex Roles, 39, 153-164. doi:10.1023/A:1018890118950

Paek, H., Nelson, M., \& Vilela, A. (2011). Examination of gender-role protrayals in television advertising across seven countries. Sex Roles, 64, 192-207. doi: 10.1007/s111990109850-y

Poata-Smith, E. (1996). He pokeke uenuku i tu ai: The evolution of contemporary Maori protest. In P. Spoonley, C. Macpherson \& D. Pearson (Eds.), Nga patai: Racism and ethnic relations in Aotearoa/New Zealand (pp. 160-179). Palmerston North: Dunmore Press.

Pyke, K. \& Johnson, D. (2003). Asian American women and racialized femininities: 'Doing' gender across cultural worlds. Gender \& Society, 17, 33-53. doi: 10.1177/0891243202238977

Ringold, D. (2008). Accounting for diversity: Policy design and Maori development in New Zealand. In A. Ahmad Dani \& A. de Haan (Eds.), Inclusive states: Social policy and structural inequalities (pp. 271-294). Washington, DC: The World Bank. 
Scherer, J. \& Jackson, S. (2008). Cultural studies and the circuit of culture: Advertising, promotional culture and the New Zealand All Blacks. Cultural Studies $\Leftrightarrow$ Critical Methodologies, 8, 507-526. doi: 10.1177/1532708608321577

Scott, M. (1990). Whitewash: The acceptable image in television advertising. In P. Spoonley \& W. Hirsh (Eds.), Between the lines: Racism and the New Zealand media (pp. 84-89). Auckland: Heinemann Reed.

Seiter, E. (1995). Different children, different dreams: Racial representation in advertising. In G. Dines \& J. Humez (Eds.), Gender, race and culture in media (pp. 99-108). London: Sage.

Statistics New Zealand. (2006). Quick stats about culture and identity. Retrieved from www.statistics.govt.nz/Census/2006CensusHomePage/QuickStats/quickstats-about-asubject/culture-and-identity.aspx

Statistics New Zealand. (2007). Information and communication technology in New Zealand: 2006. Wellington: Statistics New Zealand.

Stern, B. (1999). Gender and multicultural issues in advertising: Stages on the research highway. Journal of Advertising, 28, 1-9. Retrieved from http://www.jstor.org/stable/4189096

Taylor, C., \& Stern, B. (1997). Asian Americans: Television advertising and the "model minority" stereotype. Journal of Advertising, 26, 47-61. Retrieved from http://www.jstor.org/stable/4189033

Taylor, J. (1997). Racialized representations in British and American advertising. Area, 29, 160-171.

Turner, J. S. (2010). Sex and the spectacle of music videos: An examination of the portrayal of race and sexuality in music videos. Sex Roles, 64, 173-191. doi: 10.1007/s11199-010-9766-6

Wall, M. (1997). Stereotypical constructions of the Māori 'race' in the media. New Zealand Geographer, 53, 40-45.

Wajcman, J. (1991). Feminism confronts technology. Pennsylvania: Penn State University Press.

Wilkes, R.E. \& Valencia, H. (1989). Hispanics and Blacks in television commercials. Journal of Advertising, 18, 19-25.

Wilson, C. \& Gutierrez, F. (1995). Race, multiculturalism, and the mass media: From mass to class communication. Thousand Oaks, CA: Sage.

Wolin, L. D. (2003). Gender issues in advertising - An oversight of research: 1970-2002. Journal of Advertising Research, 43, 111-129. 